\title{
Local Plastic Instabilities of Perforated Thin-Walled Bars - FEM Modelling and DIC Verification
}

Andrzej Piotrowski ${ }^{1, a^{\star}}$, Marcin Gajewski ${ }^{1, b}$ and Cezary Ajdukiewicz ${ }^{1, c}$

${ }^{1}$ Warsaw University of Technology, Civil Engineering Department, Armii Ludowej 16 Street, 00-637 Warsaw, Poland

aa.piotrowski@il.pw.edu.pl, 'bm.gajewski@il.pw.edu.pl, cc.ajdukiewicz@il.pw.edu.pl

Keywords: Finite Element Method Modelling, Digital Image Correlation, Buckling, Critical Forces, Post-Critical Modes, Thin-Walled Bars, Perforated Bars

\begin{abstract}
In this paper results of testing and modelling of perforated thin-walled bars of low slenderness are shown. Tested and modelled elements in general are used as structural elements for storage systems. In such case the compression mode is dominant, so the proper understanding of the element behaviour in post-critical stage is essential for system safety estimation. To predict post critical behaviour the suitable constitutive models of elasto-plasticity are needed. The most essential to such simulations is the fact that local deformations and rotation angles are significant, so the large deformation modelling regarding to geometry and constitutive models have to be used. In the paper for FEM (finite element method) modelling the ABAQUS system is used, and obtained solutions are verified experimentally using Instron 8802 universal testing machine. Aside from measuring critical forces and final deformations for several samples and eight different bar's lengths, also strain and displacement fields were verified with application of DIC (digital image correlation) system ARAMIS. Because of the testing machine and DIC system limitations only very low slenderness $(1 \div 11)$ samples were taken into account. Bars of such a low slenderness should be treated as shells or three dimensional objects in numerical modelling.
\end{abstract}

\section{Introduction}

Storage systems are one of the most popular applications of perforated thin-walled bars, but the design rules for such systems can give results on the unsafe side [1], leading to many dangerous situations (structure failures) and financial losses. The paper presents results of experiments and numerical modelling of compression tests of elements presented in Fig.1. These elements are taken from a real storage system partially destroyed because of the accumulated damage created by the light impacts with the forklifts operating in the magazine area. It is the continuation of work presented on XXII, XXIII and XXIV LSCE conferences: thin-walled bars theory [2-6] calculations as well as finite element method modelling [4, 7-10] were presented in paper [11], elastic buckling modes were analysed in paper [12] and experimental results can be found in paper [13]. Some very early experiments and calculations were also presented in paper [14]. Paper [15] presents some experimental results, especially displacement fields registered with ARAMIS system. In the previous papers only some small, then studied parts of research were presented. This paper gives the general, less detailed, but more complete view on the project. It shortly presents and compares most recent and complete results obtained by the various methods.

\section{Description of elements used for numerical and experimental tests}

Elements chosen for testing are presented on Fig. 1 and are made from a typical low carbon steel [13]. They were fixed on both ends and compressed statically without any eccentricity. Lengths 
of the tested samples were 50, 100, 150, 200, 250, 300, 400 and $500 \mathrm{~mm}$, which corresponds to slenderness varying from 1 to 11 .

For the analysis presented in this paper eight finite element method models were created in ABAQUS software. Each model consists of shell elements - mainly S4R but also a small number of S3 elements. Both kinds are elements with linear shape functions and reduced integration, S4R - quadrangular and S3 - triangular. Mesh was created using the automatic ABAQUS' module and the triangular elements are used near the perforations, as it would be much more difficult, if even possible, to use only quadrangular elements in these places.

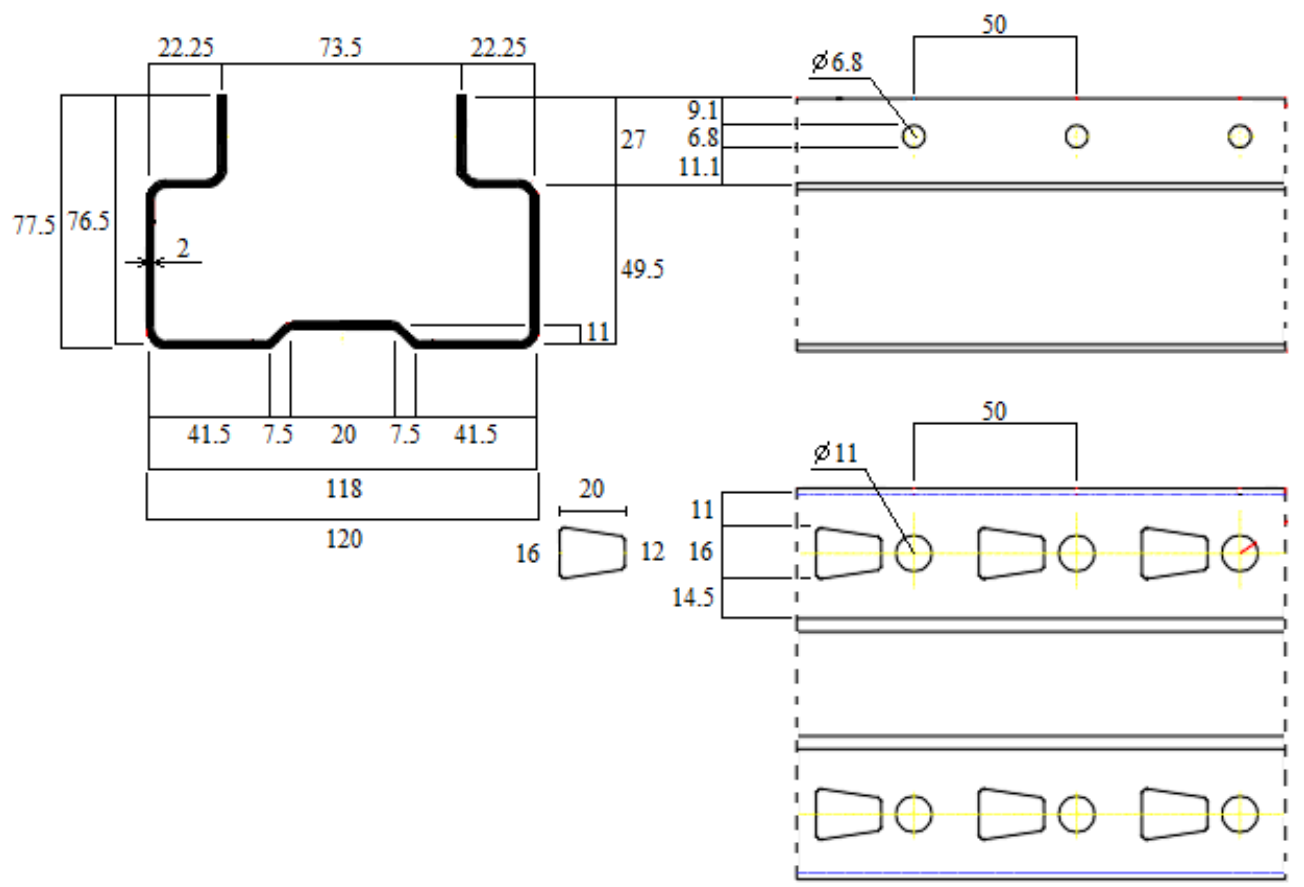

Fig. 1. Characteristic dimensions of tested elements [14].

Approximate size for the global seed was $2 \mathrm{~mm}$. Table 1 presents how many elements of each type were used in the models. The displacement type boundary conditions were applied to the nodes lying at the ends of the modelled bars. For the fixed boundary conditions all of the DOFs were blocked. One end of the bar was fully fixed and displacement causing the compression was applied to the nodes lying at the other end of the bar.

Table 1. Numbers of elements used in the models:

\begin{tabular}{|c|c|c|c|c|c|c|c|c|}
\hline \multirow{2}{*}{$\begin{array}{c}\text { Element } \\
\text { type }\end{array}$} & \multicolumn{8}{|c|}{ Number of elements for models of length equal to: } \\
\cline { 2 - 10 } & $50 \mathrm{~mm}$ & $100 \mathrm{~mm}$ & $150 \mathrm{~mm}$ & $200 \mathrm{~mm}$ & $250 \mathrm{~mm}$ & $300 \mathrm{~mm}$ & $400 \mathrm{~mm}$ & $500 \mathrm{~mm}$ \\
\hline S4R & 3946 & 7794 & 11681 & 15569 & 19448 & 23337 & 31125 & 38938 \\
\hline S3 & 42 & 82 & 140 & 170 & 218 & 244 & 340 & 440 \\
\hline
\end{tabular}

The quasi-static displacement-controlled analysis by ABAQUS/Standard with large deformation theory (NLGEOM option) was used. Solution technique was full Newton and time increment was automatically adjusted (maximum number of increments was 1000, initial increment size was 0.01, and minimum increment size was 1E-007). 
The analysed bars were made from low carbon steel [15]. It is treated as an isotropic material and described through elasto-plastic constitutive model. In elasticity range material is characterized as linear with Young modulus equal to $230 \mathrm{GPa}$ and Poisson ratio equal to 0.3. Material becomes plastic after crossing Huber-Mises yield criterion. The permanent deformation is calculated on the basis of associated with yield condition flow rule leading to plastic part of the logarithmic strain tensor [7]. Strain hardening/softening is assumed as isotropic one. The parameters for both elasticity and plasticity were determined based on laboratory experiments. For application of the large deformation theory implemented in ABAQUS proper material data preparation is needed [16]. Therefore, Piola stress axial component was recalculated onto Cauchy stress and nominal strain was recalculated onto logarithmic strain tensor axial component [7].

\section{Description of experimental tests and obtained results}

Tested samples were mounted in Instron 8802 universal testing machine using compressing plates with $5 \mathrm{~mm}$ fixtures (see Fig. 2). They were compressed with the displacement speed calculated as $4 \%$ of initial length per minute and the test was ended, when the distance between compression plates was equal to the $90 \%$ of its initial value. Force and displacement were recorded during the test with the testing machine, and the chosen permanent displacements were measured manually after the test ended [13]. Whole process was also analyzed [15] using ARAMIS digital image correlation system [17].

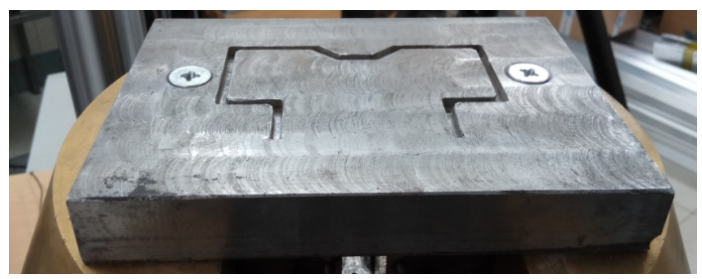

Fig. 2. Compressing plates with fixtures [13].

Three buckling modes were observed (see Fig. 3.). In the experiments the first (fully local) mode was characteristic for the shortest elements (50 mm and $100 \mathrm{~mm}$ length), the second mode for the elements longer than $150 \mathrm{~mm}$ and the third mode was possible to obtain in the longest (500 mm long) samples through grinding their ends and in the result - adding some eccentricity. $150 \mathrm{~mm}$ long samples are the border between two main buckling modes and because of that can be destroyed in the many ways combining both of them. In the numerical modelling the first mode was also characteristic for the shortest elements (50 mm and $100 \mathrm{~mm}$ length) and from 150 $\mathrm{mm}$ onwards both second and third mode were possible in every case.

First mode:

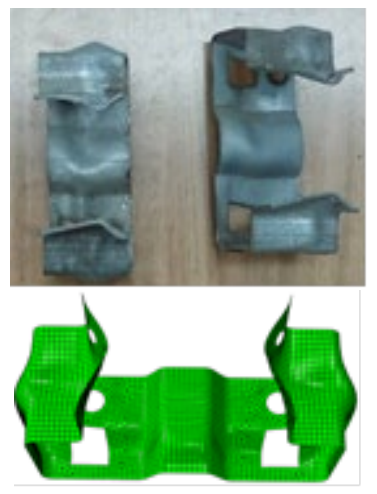

Second mode:

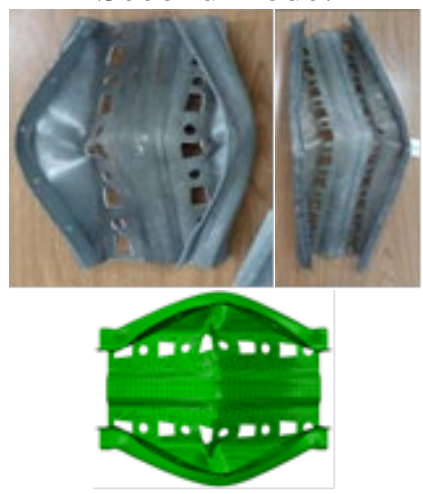

Fig. 3. Buckling modes.
Third mode:

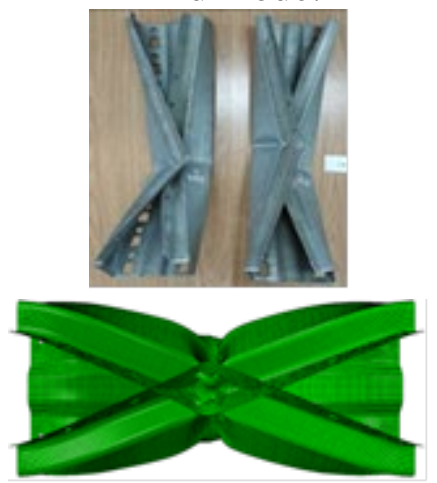


Comparison of Huber-Mises strains acquired from experiment and Huber-Mises stresses acquired from FEM modelling shows good quality compliance (see Fig. 4.).

(a)

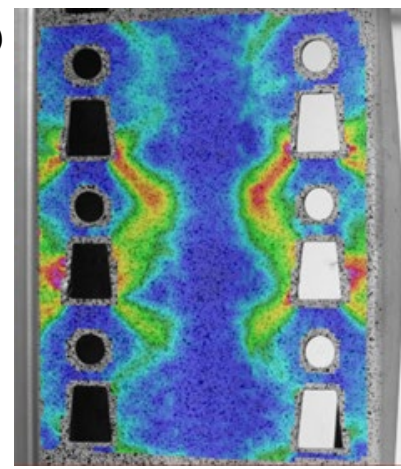

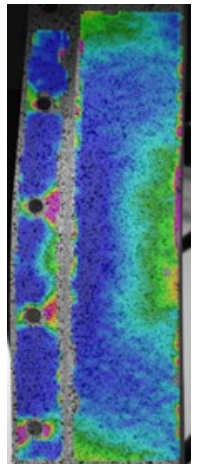

(b)

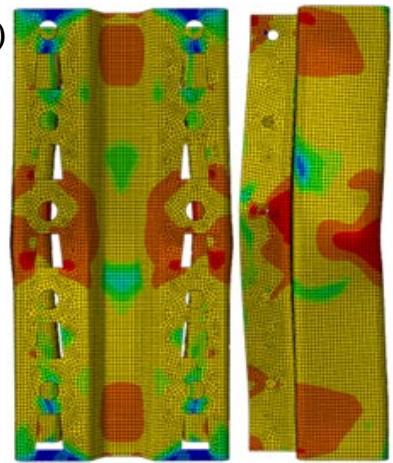

Fig. 4. Huber-Mises strain field from Aramis DIC system (a) and Huber-Mises stress field from Abaqus FEM software (b) for the $250 \mathrm{~mm}$ long sample.

Equilibrium paths acquired from experiment and calculations for two chosen lengths are shown in Fig. 5. Experimental data are presented without any processing, especially initial fitting stages are not cut from the graphs.
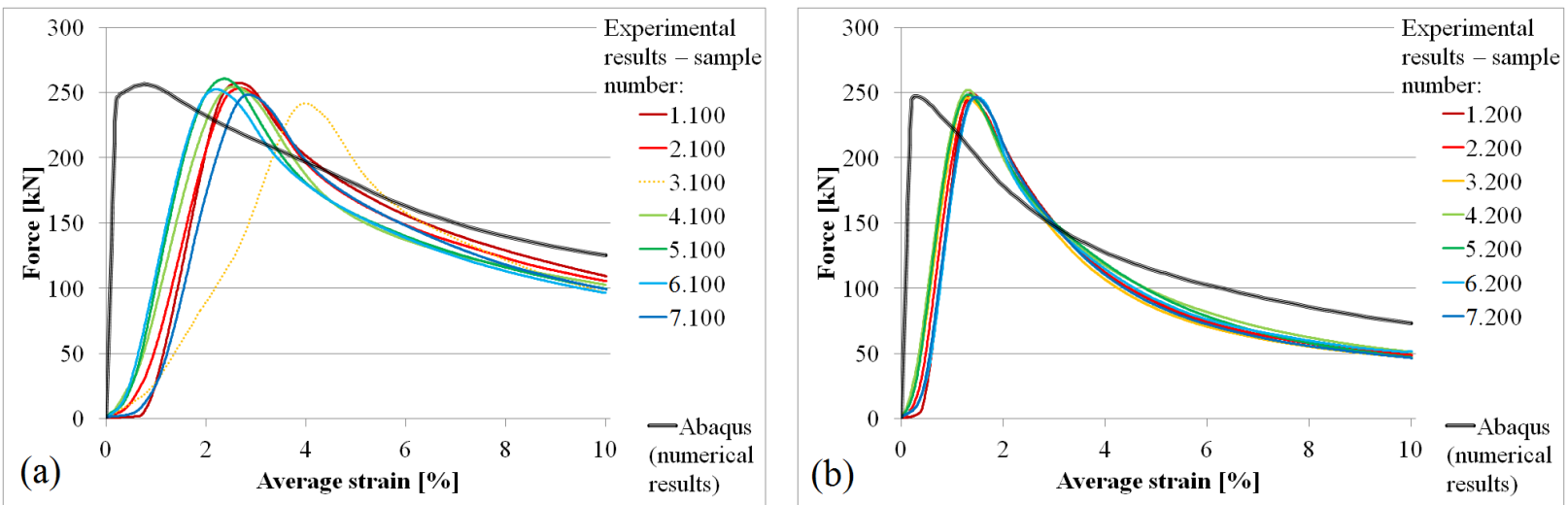

Fig. 5. Equilibrium paths from experiment (without DICS or extensometers) and finite element method modelling for $100 \mathrm{~mm}$ (a) and $200 \mathrm{~mm}$ (b) bars.
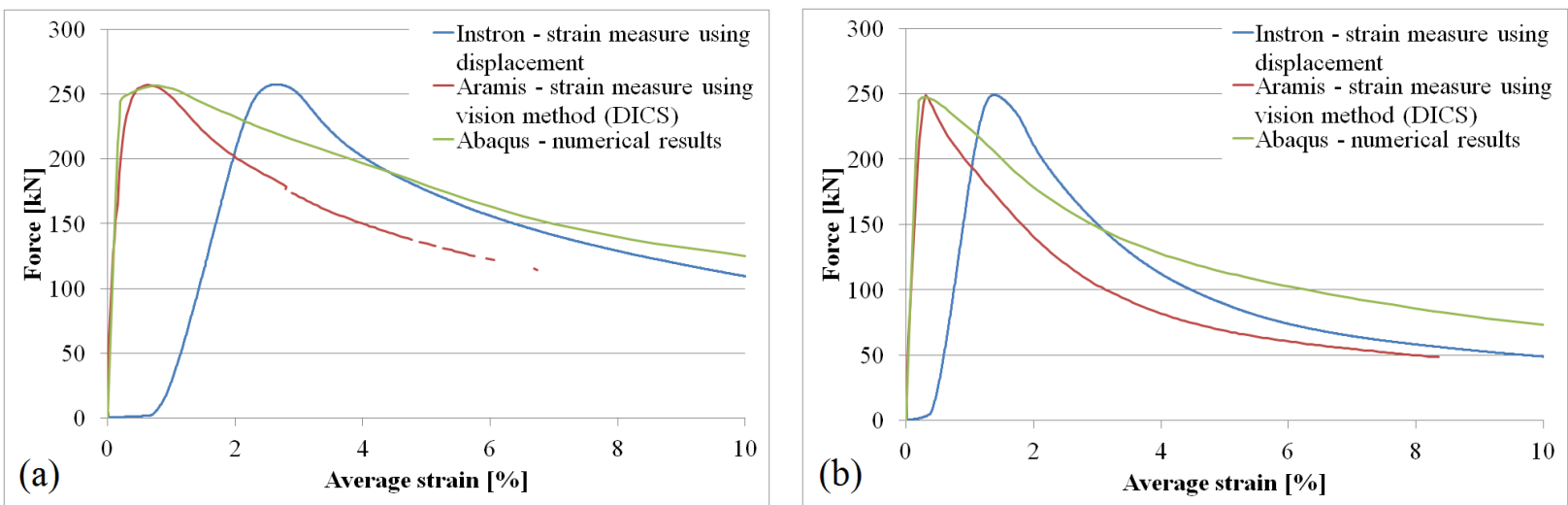

Fig. 6. Equilibrium paths from experiment (with and without DICS) and finite element method modelling for $100 \mathrm{~mm}$ (a) and $200 \mathrm{~mm}$ (b) bars.

Using Aramis digital image correlation system for acquiring strains instead of evaluating it from machine data gives better results and better compliance with theoretical results (see Fig. 6.). 

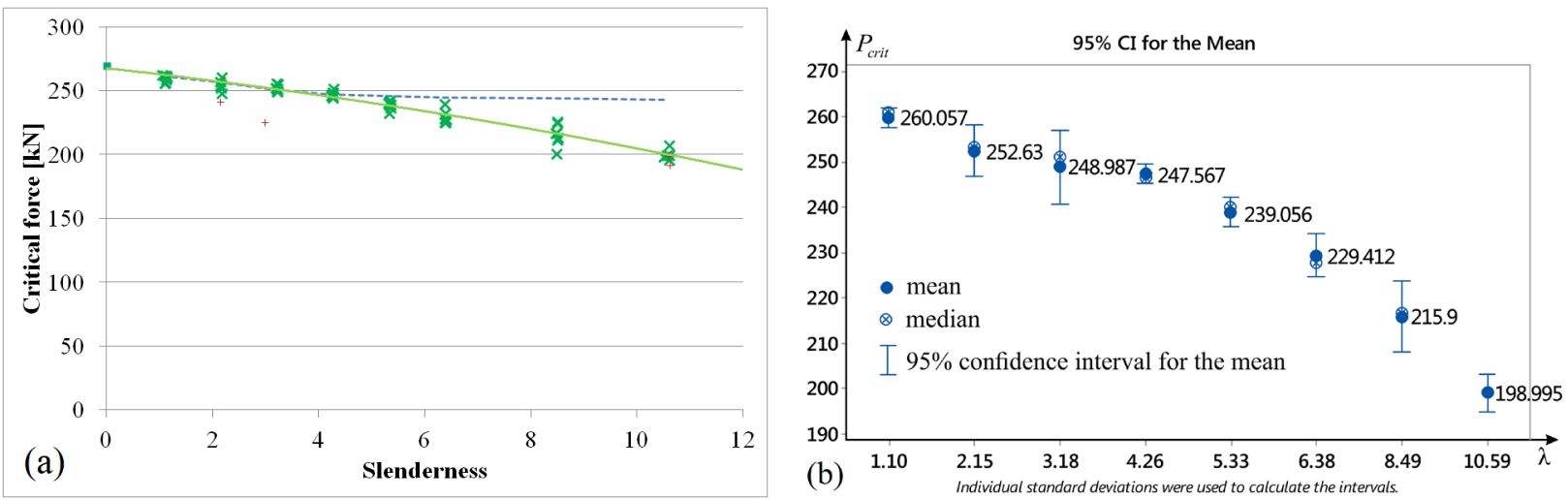

Fig. 7. Critical force in the function of slenderness: green - experiment, blue - FEM calculations (a), and statistical analysis of experimental results (b).

Critical forces, understood as maximum forces acquired during the tests, are correctly predicted for elements shorter or equal $20 \mathrm{~cm}$. For longer elements calculations give higher values than observed in reality (see Fig. 7.).

\section{Summary}

Comparison of numerical and experimental results shows good quality compliance. Buckling modes are correctly predicted (Fig. 3.) and areas of the biggest strains are also identified properly (Fig. 4.). Formation of the curved fields of high strains connecting perforations can be observed as the most important part of the buckling process, especially in the shortest samples, in which the buckling is plastic and local. Critical forces are correctly predicted only for the shortest elements (up to $20 \mathrm{~cm}$ of length - see Fig. 7.). Possible reasons for overestimation of this value in the longer ones are boundary conditions (fixed in theory and in reality realised as shown on Fig. 2.) and imperfections (thin-walled bars can be very sensitive to even the smallest differences between theoretical and real geometry [18]). Elastic phase of compression is properly modelled, in the plastic phase some differences between model and experiment can be observed (Fig. 6.). When comparing theoretical and experimental results acquiring correct strains from experiment is very important. It can be done by using extensometers or digital image correlation system. Ignoring this can result in big errors because of the problem of contact between tested samples and compression plates (see Fig. 5.). Further work is necessary: better modelling of fixed boundary conditions, testing elements with hinged boundary conditions, investigating imperfections, trying different material models and better determination of parameters for them (for example reverse analysis).

\section{References}

[1] C. Bernuzzi, F. Maxenti, European alternatives to design perforated thin-walled cold-formed beam-columns for steel storage systems, J CONSTR STEEL RES, 110 (2015) 121-136. https://doi.org/10.1016/j.jcsr.2015.02.021

[2] M. Kotelko, Load capacity and mechanisms of destruction of thin-walled structures, Wydawnictwo Naukowo-Techniczne, Warsaw, 2011 (in Polish).

[3] J. Mutermilch, A. Kociolek, Strength and stability of thin-walled bars with open crosssection. Warsaw University of Technology Publishing House, Warsaw, 1964 (in Polish).

[4] M. Nedelcu, Buckling mode identification of perforated thin-walled members by using GBT and shell FEA, Thin-Walled Structures 82 (2014) 67-81.

https://doi.org/10.1016/j.tws.2014.04.005 
[5] J.B. Obrebski, Thin-walled elastic bars, Warsaw University of Technology Publishing House, Warsaw, 1991 (in Polish).

[6] S. Piechnik, Thin-walled bars with open cross-section, Cracow University of Technology Publishing House, Cracow, 2000 (in Polish).

[7] ABAQUS User’s manual, ver. 6.11. Dassault Systèmes, SIMULIA (2011)

130.149.89.49:2080/v6.11/ (access on 08-03-2019).

[8] G. Rakowski, Z. Kacprzyk, Finite element method in structural mechanics, Warsaw University of Technology Publishing House, Warsaw, 2016 (in Polish).

[9] O.C. Zienkiewicz, R.L. Taylor, The finite element method for solid and structural mechanics, Sixth edition, Elsevier Butterworth Heinemann, 2005.

[10] O.C. Zienkiewicz, R.L. Taylor, J.Z. Zhu, The finite element method - Its basis \& fundamentals, Sixth edition, Elsevier Butterworth Heinemann, 2005.

[11] L. Kowalewski, A. Piotrowski, M. Gajewski, S. Jemiolo, FEM application for determination of post-critical deformation modes of perforated thin-walled bars, in: Monograph from Scientific Seminar Organized by Polish Chapters of International Association for Shell and Spatial Structures, University of Warmia and Mazury, Faculty of Geodesy, Geospatial and Civil Engineering, XXII LSCE - 2016, Olsztyn, 2016, pp. 27-30.

[12] L. Kowalewski, A. Piotrowski, M. Gajewski, S. Jemiolo, Determination of critical forces with corresponding deformation modes for perforated thin-walled bars, in: Monograph from Scientific Seminar Organized by Polish Chapters of International Association for Shell and Spatial Structures, University Science and Technology, Faculty of Civil Engineering, Architecture and Environmental Engineering, XXIII LSCE - 2017, Bydgoszcz, 2017, pp. 14-17. [13] A. Piotrowski, M. Gajewski, C. Ajdukiewicz, L. Kowalewski, S. Jemiolo, Experimental and numerical determination of critical forces for perforated thin walled bars, in: Monograph from Scientific Conference of IASS Polish Chapters, Lodz University of Technology, XXIV LSCE 2018, Lodz, 2018, pp. 109-114.

[14] A. Piotrowski, L. Kowalewski, R. Szczerba, M. Gajewski, S. Jemiolo, Buckling resistance assessment of thin-walled open section element under pure compression, MATEC Web of Conferences, Vol. 86, Article Number: 01021, 2016. https://doi.org/10.1051/matecconf/20168601021

[15] A. Piotrowski, M. Gajewski, C. Ajdukiewicz, Application of digital image correlation system for analysis of local plastic instabilities of perforated thin-walled bars, MATEC Web of Conferences, Vol. 196, Article Number: 01032, 2018.

https://doi.org/10.1051/matecconf/201819601032

[16] S. Jemiolo, M. Gajewski: Hyperelasto-plasticity. Warsaw University of Technology Publishing House, Warsaw 2017 (in Polish).

[17] Aramis v6.1 User Manual, GOM Gmbh (2008)

materials-science.phys.rug.nl/index.php/home/downloads/category/1manuals?download=27\%3Aaramis-v61.J (access on 08-03-2019).

[18] P. Paczos, J. Kasprzak, Influence of actual imperfections on the strength and stability of cold-formed thin-walled C-beam, 28th Symposium of Experimental Mechanics of Solids, Jachranka, 2018. 